\title{
Simulation of solidification during crystallization under pressure
}

\author{
Richard Pastirčák ${ }^{1 *}$, Marek Brůna ${ }^{1}$, Dana Bolibruchová $^{1}$ \\ Department of technological engineering, University of Žilina, Univerzitná 8215/1, \\ 01026 Žilina.
}

\begin{abstract}
The paper deals with squeeze casting technology. The influence of process parameters variation (casting temperature, mold temperature, pressure) will be observed. The experimentally obtained boundary conditions (heat flow, HTC) will be verified using the ProCast simulation software. Shape influence on the mold filling process and the temperature field under pressure will be evaluated. To evaluate the mechanical properties, a tensile test was performed. Three identical samples were cast for each parameters change. From these samples the average values of the mechanical properties were measured and calculated. The thickness of the flat test samples was $3.15,4,5,6.3,8 \mathrm{~mm}$ with a sample width of $10 \mathrm{~mm}$. For gravity cast of the casting, the mechanical properties of the thinner parts were higher. At the pressure influenced castings, the mechanical properties were higher in the thicker parts of the casting.
\end{abstract}

Keywords: squeeze casting, heat flow, HTC, pressure, simulation

\section{Introduction}

The squeeze casting technology, which was used in experimental verification of the heat transfer is a relatively unusual method. This is due, in particular, to little experience with practical use combined with the low lifetime of the mold, which is caused by high thermal and mechanical stresses combined with a long cycle time. With direct squeeze casting, the cycle time can be up to about 1 minute. Such stress greatly reduces the life of the mold [1, $3,9,12]$. The main characteristics of this method, which are distinguishing it from conventional high-pressure casting include, in particular, the slow filling of the melt into the mold cavity (roughly $0.5 \mathrm{~m} . \mathrm{s}^{-1}$ ) and considerably larger gates, than those used in the high-pressure casting. The slow filling of the mold cavity guarantees a laminar flow without turbulences. In addition, a longer filling time allows evacuation of gases from the mold cavity, which reduces the resulting porosity of the casting. Thanks to the large slit, the melt and later the casting itself are constantly under the influence of the applied pressure, while the gates solidified as last. This allows continuous melt substitution in interdendritic areas. The result of this is high integrity and minimum casting porosity. This also prevents the creation of various foundry defects. These castings shows high mechanical properties, which can be further increased by subsequent heat treatment. $[2,4,8,11]$ The pressure at

\footnotetext{
${ }^{*}$ Corresponding author: richard.pastircak@fstroj.uniza.sk

Reviewers: Eva Tillová, Milan Žmindák
} 
squeeze casting is from 30 to $150 \mathrm{MPa}$, depending on the type of alloy used, the casting temperature, and more. The pressure itself prevents the formation of an air gap, which is normally formed at the gravity casting between the casting and the mold. This air gap substantially slows heat transfer and thus also the cooling rate of the casting. By eliminating the gap due to pressure, there are significant changes in the structure and also in the mechanical properties of the material. In The structure, the grains size of the primary structure is reduces and also is change the morphology of eutectic silicon and intermetallic phases, which act less harmful. The resulting structure is finer and more uniform throughout the volume. The concentration of silicon in the eutectic and the volume ratio of the primary $\alpha$-phase is increased and the volume of the eutectic in the structure is reduced. The result is a change in mechanical properties, where the strength, elongation and fracture toughness are increasing. At the gravity casting achieves a better mechanical properties the parts of casting, which solidified faster, in this case is about the thinnest parts of the casting. Pressure utilization at the squeeze casting technology greatly accelerates solidification and cooling in the thicker areas of the casting. This is associated with the eliminate of an air gap formed by gravity casting. The result is a change in structure and a significant increase in mechanical properties compared to gravity casting $[1,4,5,6,7,10]$.

\section{Experimental material and process}

For the study of crystallisation under pressure, a casting with different wall thicknesses was used, which is shown in Fig. 1. The thicknesses of the individual walls were selected based on the selected numbers of the geometric series R 10 with the sequence of $3.15 \mathrm{~mm}, 4 \mathrm{~mm}$, $5 \mathrm{~mm}, 6.3 \mathrm{~mm}$ and $8 \mathrm{~mm}$. The width of each wall was $22 \mathrm{~mm}$ with a length of $100 \mathrm{~mm}$. Dimensions were chosen to evaluate the mechanical properties of individual casting walls $(\mathrm{Rm})$. The casting model was created in the SolidWorks work environment, simulation calculations were carried out in the ProCast program, and the casting process was carried out in the casting laboratory at the Department of Technological Engineering at the University of Žilina in Žilina.

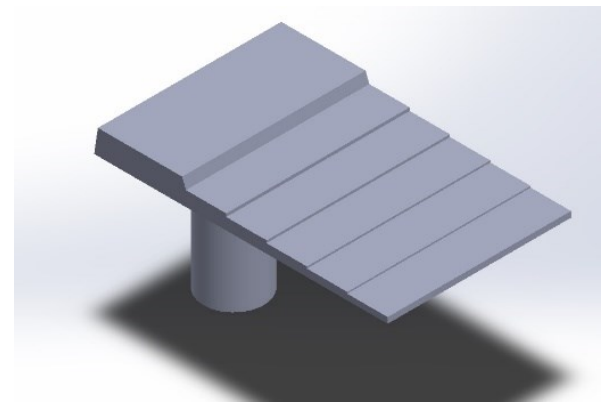

Fig. 1. Casting model

For experimental verification was used AlSi7Mg alloy, which is characterized by excellent foundry properties, especially good fluidity, allowing a better fluidity of the melt to all parts of the form. The chemical composition of the alloy used is shown in Table 1. 
Table 1. Chemical composition of the AlSi7Mg0.3 alloy

\begin{tabular}{|c|c|c|c|c|c|c|}
\hline \multicolumn{7}{|c|}{ Chemical composition of the AlSi7Mg0.3 [\%] } \\
\hline $\mathrm{Fe}$ & $\mathrm{Si}$ & $\mathrm{Mn}$ & $\mathrm{Ti}$ & $\mathrm{Cu}$ & $\mathrm{Mg}$ & $\mathrm{Zn}$ \\
\hline $\max 0.19$ & $6.5-7.5$ & $\max 0.1$ & $\max 0.25$ & $\max 0.05$ & $0.25-0.45$ & $\max 0.07$ \\
\hline
\end{tabular}

The mold was made of low-carbon steel and she was composed of two parts. The lower part of the mold copied the shape of a stepped casting. The second part was a detachable upper part of the mold with the gating system. Figure 2 shows the lower mold part (left) and upper mold part (right).

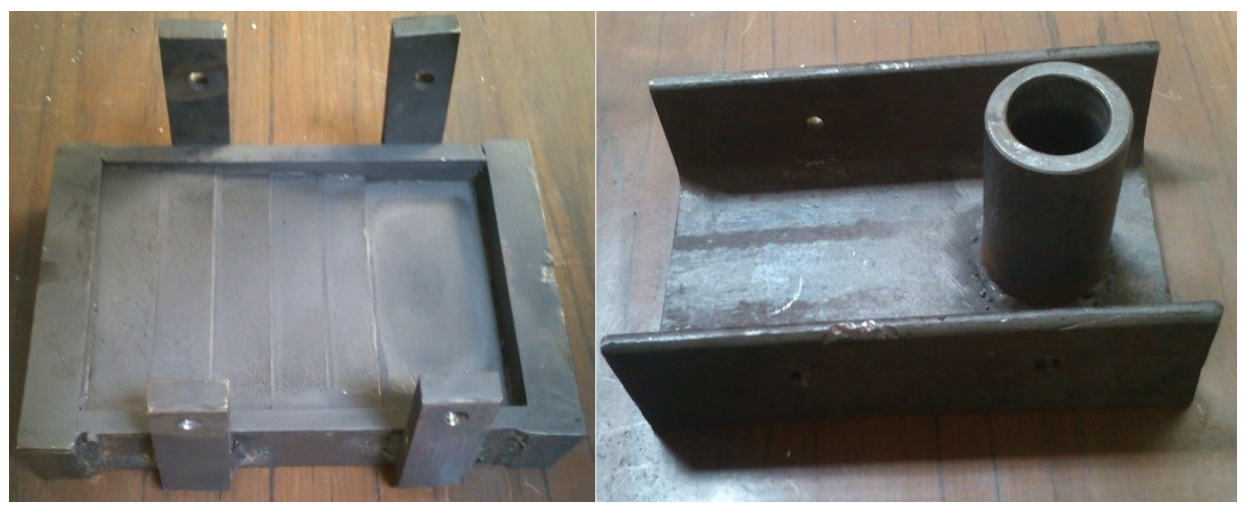

Fig. 2. The lower and the upper part of the mold

Verification of filling and solidification was carried out in the simulation program and later experimentally. In the first stage was evaluated the results of the experimental melting with the results of the simulation calculation. The main evaluations for the setting of the casting process parameters was the evaluations of the fluidity of the casting at the gravity casting. The marginal conditions for the calculation were used from the experiment, for example casting temperature, mold temperature, casting method, $\mathrm{AlSi} 7 \mathrm{Mg} 0.3$ alloy as material of the casting and low carbon steel as material of the mold. Casting time was $3.2 \mathrm{~s}$. The fluidity of the material was defined as a critical proportion of the solid phase of $25 \%$. The calculation network consisted from 199,647 elements.

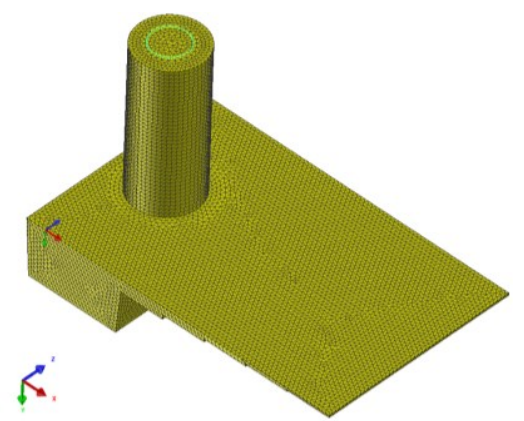

Fig. 3. Geometric design of a casting with a calculation network 
The results of the simulation calculation proved, that by the selected parameters do not cause the fluidity of the casting in the full volume, as can be seen in Fig. 4 and 5, which was also confirmed experimentally.
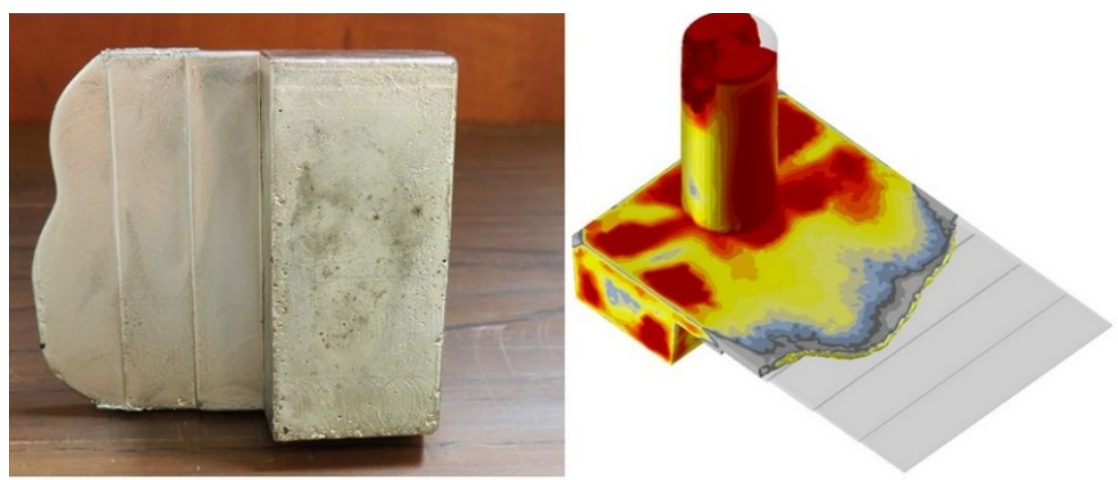

Fig. 4. Comparison of casting after completion of the first casting and the first simulation for the first casting design at a mold temperature of $200^{\circ} \mathrm{C}$ and a casting temperature of $720^{\circ} \mathrm{C}$
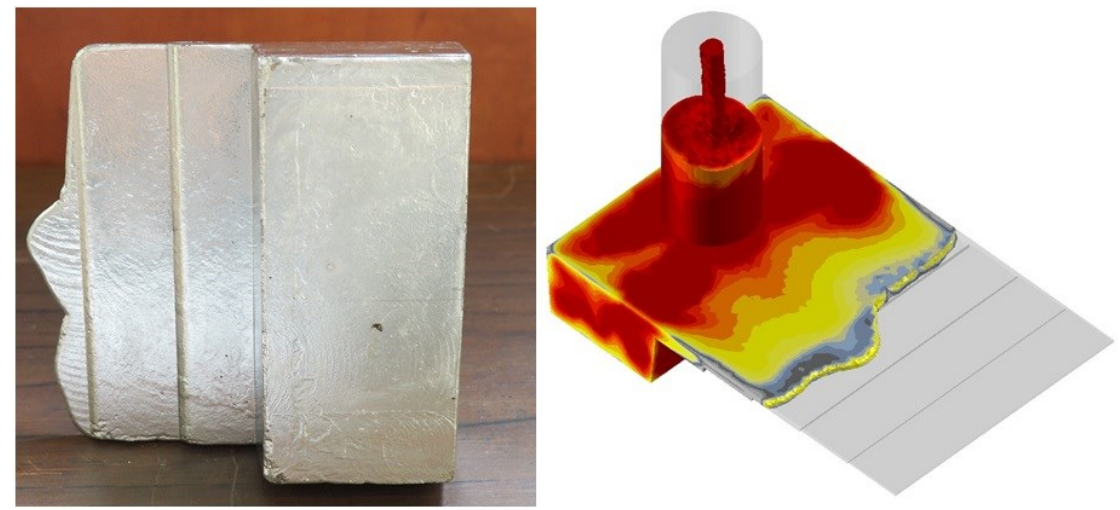

Fig. 5. Comparison of casting after completion of second casting and additional simulation for the first casting design at a mold temperature of $350^{\circ} \mathrm{C}$ and a casting temperature of $750{ }^{\circ} \mathrm{C}$

After verifying the suitability of the proposed marginal and initial simulation calculation conditions, the geometric modification of the model was performed. At the same time, a geometric modification the depth of the inlet part of the melt was proposed in the space under the gating system. The original height of $30 \mathrm{~mm}$ was reduced to a half of $15 \mathrm{~mm}$.

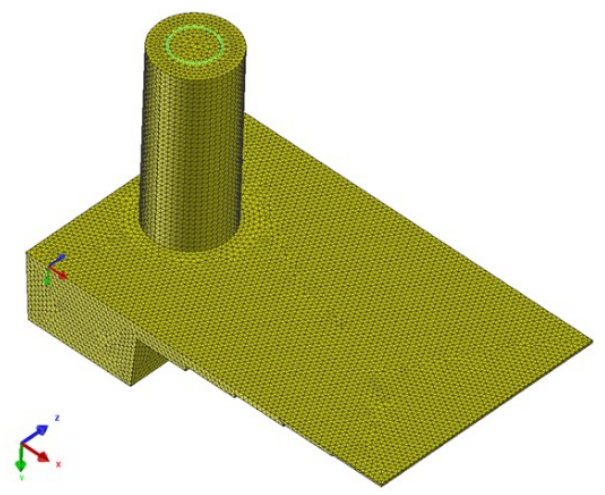

Fig. 6. Geometric design of a casting with a calculation network 
The geometric model of the final casting, which was created in SolidWorks. The simulation network is shown in Fig. 6. The network consists from 158834 elements. The simulation parameters are casting temperatures 720 and $730^{\circ} \mathrm{C}$, mold temperature $250{ }^{\circ} \mathrm{C}$, casting time $3.2 \mathrm{~s}$, velocity of the free surface at the mold wall 0.7 and critical proportion of solid phase $25 \%$. As can be seen in Fig. 7, the results of the simulation calculation showed, that the modifications in the modeled casting caused to fluidity of the melt in almost the entire volume.
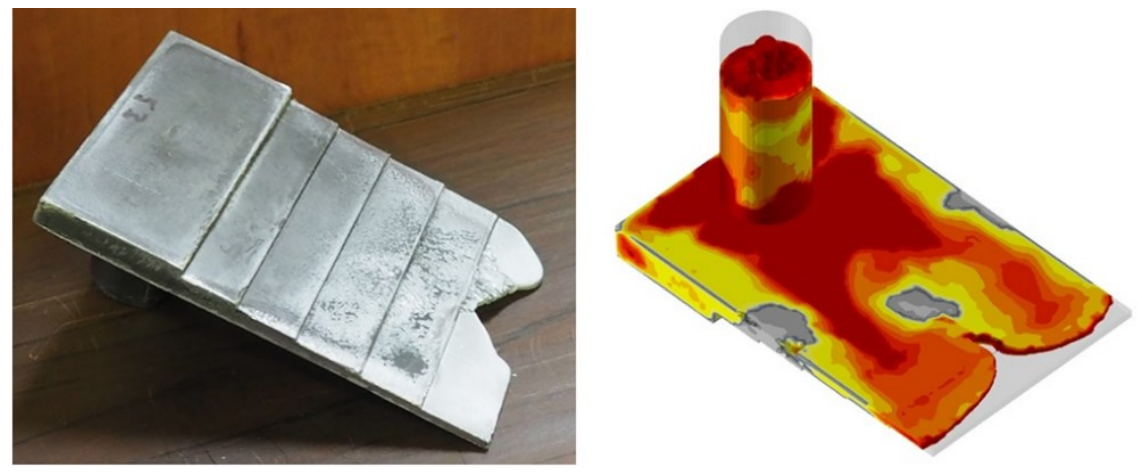

Fig. 7. The proportion of solid phase in the casting after completion of the simulation at a mold temperature of $200^{\circ} \mathrm{C}$ and a casting temperature of $720^{\circ} \mathrm{C}$

Based on the results of the simulation calculation, a change of casting parameters was proposed to casting temperature $730^{\circ} \mathrm{C}$ and mold temperature $250^{\circ} \mathrm{C}$. The results of the simulation calculation as well as the experimental verification confirmed the complete filling of the mold cavity during gravity casting, Fig. 8 .
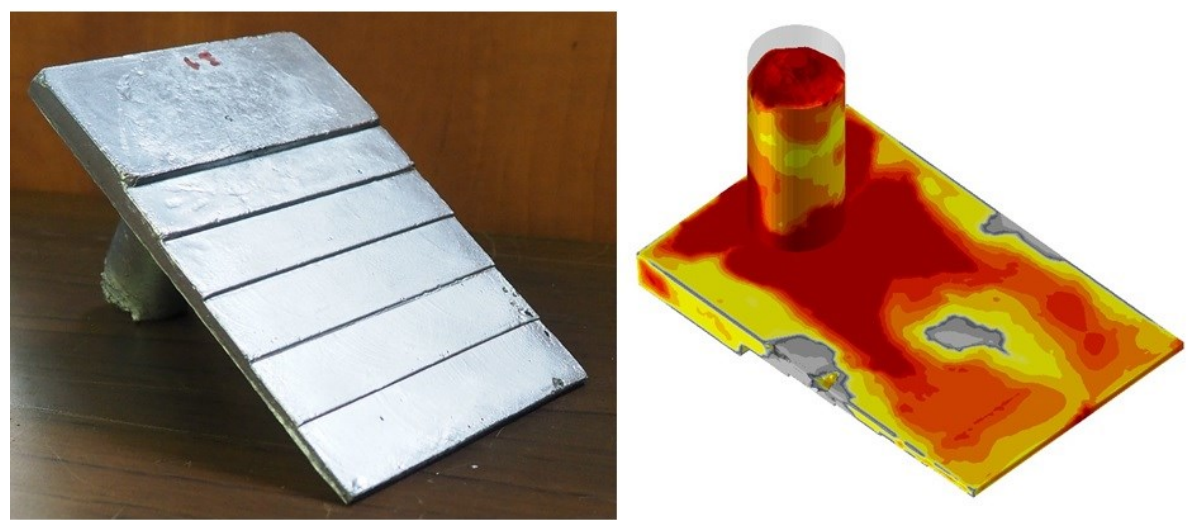

Fig. 8. Comparison of casting after completion of second casting and additional simulation for final casting design, at mold temperature $250^{\circ} \mathrm{C}$ and casting temperature $730^{\circ} \mathrm{C}$

Based on the results of the simulation calculation, an experiment for crystallisation under pressure was proposed. Casting parameters: Casting temperature $730^{\circ} \mathrm{C}$, mold temperature $250^{\circ} \mathrm{C}$, pressure $30 \mathrm{MPa}$, start of pressure was shortened to $2.5 \mathrm{~s}$ from the start of casting. 


\section{Results}

By defining the casting process with crystallisation under pressure, the simulation calculations and experimental casting were performed. The basic casting parameters are shown in Table 2. The time of the applied pressure was 40 seconds.

Table 2. Casting parameters of individual samples

\begin{tabular}{|c|c|c|c|}
\hline Casting & $\begin{array}{c}\text { Mold temperature } \\
{\left[{ }^{\circ} \mathbf{C}\right]}\end{array}$ & $\begin{array}{c}\text { Pouring temperature } \\
{\left[{ }^{\circ} \mathbf{C}\right]}\end{array}$ & $\begin{array}{c}\text { Pressure } \\
{[\mathbf{M P a}]}\end{array}$ \\
\hline 1. & 250 & 730 & 0.1 \\
\hline 2. & 250 & 730 & 30 \\
\hline 3. & 200 & 735 & 30 \\
\hline 4. & 150 & 740 & 30 \\
\hline
\end{tabular}

In Fig. 8 is shown the results of the simulation calculation at the individual casting conditions. The presented results represent the proportion of the solid phase at the time from begin of applied pressure to the melt. In Fig. 9-10 is shown the total solidification time of the individual samples and the casting time between the liquidus and the solidus. These times have the most significant effect on the resulting mechanical properties of castings.

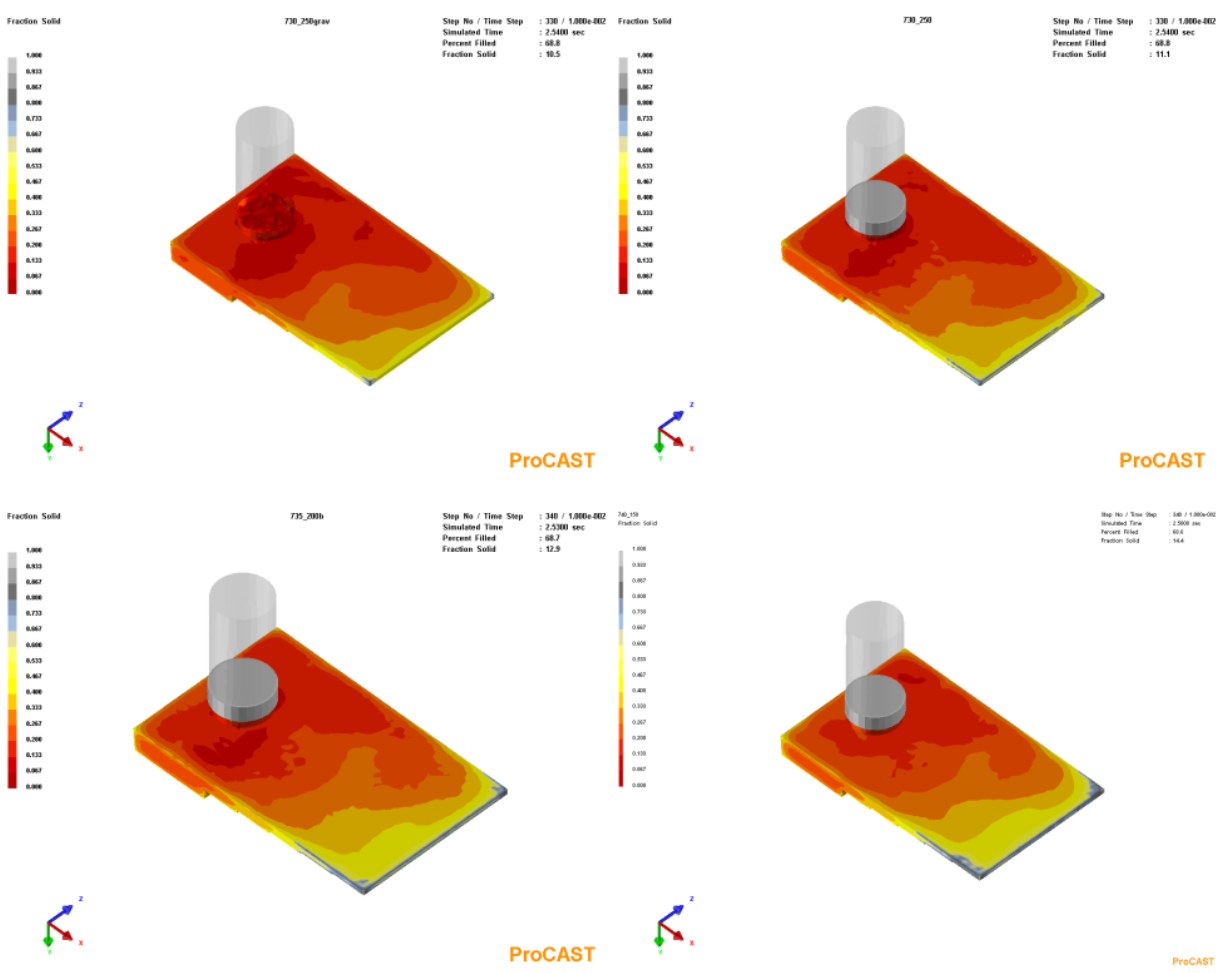

Fig. 8. The proportion of solid phase in the casting, 2.5 seconds from the start of casting 

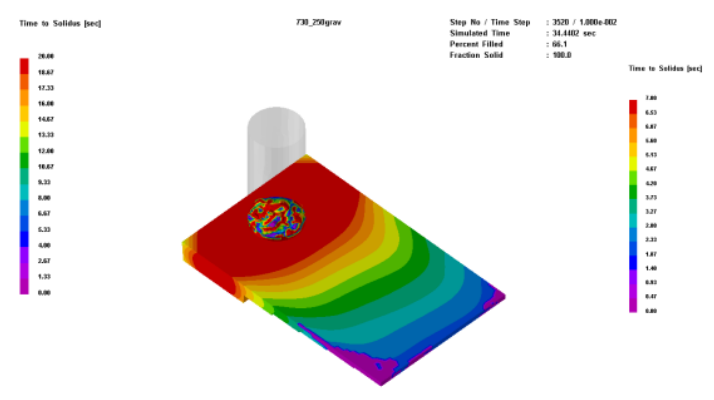

$\Sigma^{2}$

ProCAST $\zeta^{2}$

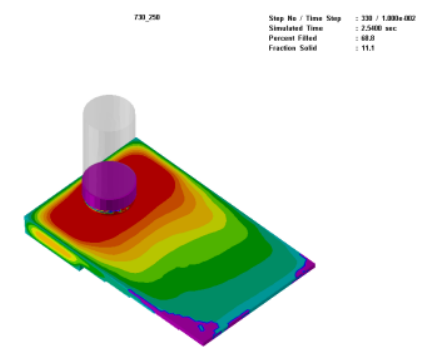

ProCAST
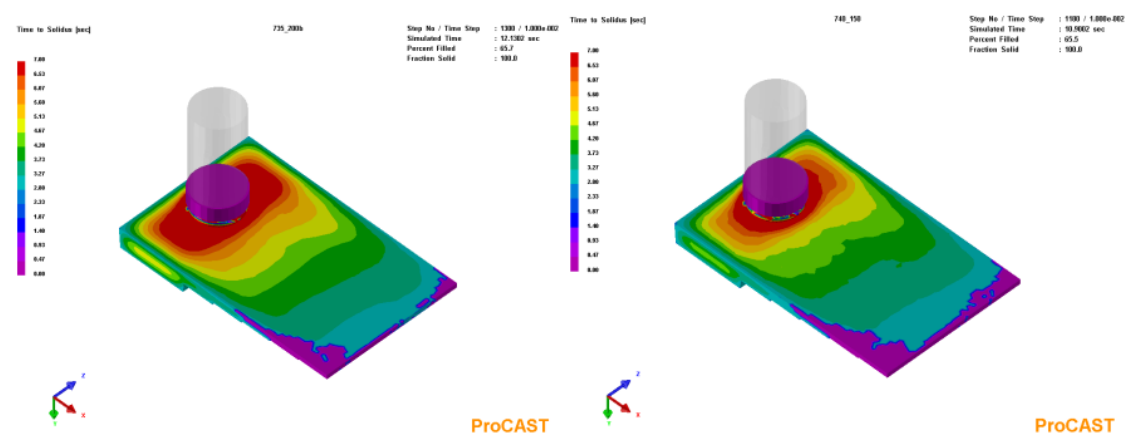

Fig. 9. Solidification time of the casting
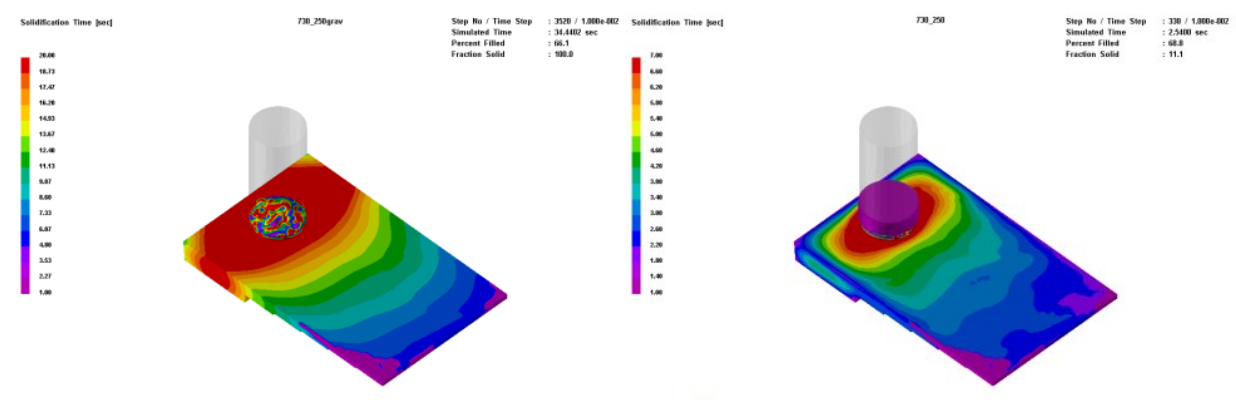

$\Sigma^{2}$
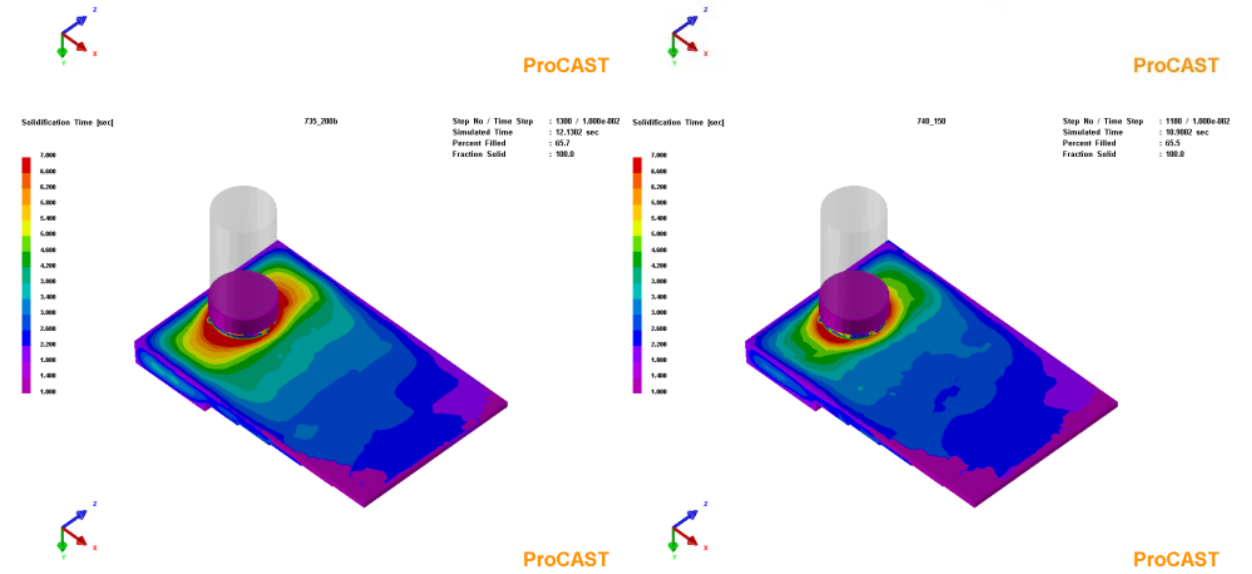

Fig. 10. Crystallization time 
To evaluate the mechanical properties, a tensile test was performed. Three identical samples were cast for each parameters change. From these samples the average values of the mechanical properties were measured and calculated. The thickness of the flat test samples was $3.15,4,5,6.3,8 \mathrm{~mm}$ with a sample width of $10 \mathrm{~mm}$. The average measured results of $\mathrm{Rm}$ for individual casting processes and their individual areas of different thicknesses are shown in Table 3.

Table 3. Results of the tensile strength for individual castings and wall thicknesses

\begin{tabular}{|c|c|c|c|c|}
\hline $\begin{array}{c}\text { Wall thickness } \\
{[\mathbf{m m}]}\end{array}$ & $\begin{array}{c}\text { Casting 1 } \\
{[\mathbf{M P a}]}\end{array}$ & $\begin{array}{c}\text { Casting 2 } \\
{[\mathbf{M P a}]}\end{array}$ & $\begin{array}{c}\text { Casting 3 } \\
{[\mathbf{M P a}]}\end{array}$ & $\begin{array}{c}\text { Casting 4 } \\
{[\mathbf{M P a}]}\end{array}$ \\
\hline $\mathbf{3 . 1 5}$ & 176 & 158 & 157 & 195 \\
\hline $\mathbf{4}$ & 170 & 198 & 170 & 191 \\
\hline $\mathbf{5}$ & 166 & 185 & 164 & 193 \\
\hline $\mathbf{6 . 3}$ & 164 & 200 & 188 & 200 \\
\hline $\mathbf{8}$ & 150 & 196 & 185 & 205 \\
\hline
\end{tabular}

\section{Conclusions}

The first stage of the experiments was aimed on defining the marginal conditions of the simulation calculation. Casting geometry has been designed with regard to the poor fluidity of casting. In the experiment, technology of the gravity casting in to metal form was used. By defining the marginal conditions, a very good match of the results of the simulation calculation with the experimental results was achieved. These modified marginal conditions were used in the next stage of experiments, in which we focused on technology of the crystallization under pressure. The geometry of the inlet has been adapted to achieve complete fluidity of the casting. The crystallization conditions under pressure were defined from the evaluation of previous experiments. The casting temperature must be at least $730^{\circ}$ C. We have adjusted the mold temperature with respect to the amount of heat contained in the casting, from 150 to $250{ }^{\circ} \mathrm{C}$. The start-up time of the pressure on the crystallizing melt was selected for $2.5 \mathrm{~s}$, in order to quickly solidify the thinnest part of the casting. The temperature field does not change significantly for the different casting conditions within 2.5 seconds. During the total casting time of the casting it can be observed that the lower mold temperature influences on the shortening of the total solidification time of the casting. From the results of the experiments is also obvious, that the solidification time of the casting at the crystallization under pressure is greatly reduced. At the gravity cast of the casting is the solidification time of the thickest part of the casting about $16 \mathrm{~s}$. At the pressure affected castings is this solidification time from 3 to 4,2 s. This effect was also confirmed in the evaluation of mechanical properties. For gravity cast of the casting, the mechanical properties of the thinner parts were higher. At the pressure influenced castings, the mechanical properties were higher in the thicker parts of the casting. The thinner parts of the casting solidify approximately as long as gravity casting. The significantly shorter solidification time of the thicker parts of the casting means, that the effect of the pressure results in the formation of a finer structure and also in the increase the tensile strength.

This work was created in the framework of the grant projekt VEGA $N^{\circ} 1 / 0494 / 17$. The authors acknowledge the grant agency for support. 


\section{References}

1. R. Pastirčák, J. Ščury, M. Brůna, D. Bolibruchová, Effect of Technological Parameters on the AlSi12 Alloy Microstructure During Crystallization Under Pressure. Archives of foundry engineering 17 (2), 75-78 (2017)

2. R. Pastirčák, J. Ščury, Effect of technological parameters on microstructure in alloy AlCu4Ti using squeeze casting. American Institute of Physics Publising, AIP conference proceedings 1745, (2016)

3. J. O. Aweda, M.B. Adeyemi, Experimental determination of heat transfer coefficients during squeeze casting of aluminium. Journal of Materials Processing Technology 2009 (3), 1477-1483 (2009)

4. J. H. Lee, H. S. Kim, C. W. Won, B. Cantor, Effect of the gap distance on the cooling behavior and the microstructure of indirect squeeze cast and gravity die cast 5083 wrought Al alloy. Materials Science \& Engineering A 338 (1-2), 182-190 (2002)

5. M. Brůna, D. Bolibruchová, R. Pastirčák, Numerical simulation of porosity for Al based alloys. Procedia Engineering 177, 488-495 (2017)

6. P. Fabian, G. Sládek, J. Bronček, I. Bilska, A. Szczotok, Electrospark alloying of carbon steel with WC-Co-Al2O3: deposition technique and coating properties. Advanced Materials Research 874, 101-106 (2014)

7. P. Pecháč, M. Sága, Controlling of local search methods' parameters in memetic algorithms using the principles of simulated annealing. Procedia Engineering 136, 70-76 (2016)

8. D. Bolibruchová, J. Macko, M. Brůna, Elimination of negative effect of Fe in secondary alloys AlSi6Cu4 (EN AC 45 000, A 319) by nickel. Archives of metallurgy and materials 59 (2), 717-721 (2014)

9. P. Kopas, L. Jakubovičová, M. Vaško, M. Handrik, Fatigue resistance of reinforcing steel bars. Procedia Engineering 136, 193-197 (2016)

10. M. Patek, M. Mičian, A. Sládek, D. Kadáš, Numerical analysis of T-joint welding with different welding sequences. Manufacturing technology : Journal for science, research and production 16 (1), 234-238 (2016)

11. D. Bolibruchová, L. Richtarech, S. M. Dobosz, K. Major-Gabrys, Utilisation of Mould Temperature Change in Eliminating the Al5FeSI Phases in Secondary AlSi7Mg0.3 Alloy. Archives of Metallurgy and Materials 62 (1), 357-362 (2017)

12. R. Koňar, M. Mičian, Ultrasonic Inspection Techniques Possibilities for Centrifugal Cast Copper Alloy. Archives of foundry engineering 17 (2), 35-38 (2017) 